\title{
田
}

\section{SOBRE O CONCEITO DE EXÉRCITO INDUSTRIAL DE RESERVA: ASPECTOS HISTÓRICOS E ATUALIDADE}

\author{
On the concept of industrial reserve army: historical aspects and current
}

\author{
Ronaldo Vielmi Fortes*
}

\begin{abstract}
RESUMO
Pretende-se neste artigo retomar a definição marxiana de exército industrial de reserva e acompanhar, pelo menos em suas linhas mais gerais, os decursos históricos dos desdobramentos de tal categoria no âmbito da dinâmica processual da sociabilidade. Consideramos que a investigação histórica do problema abre a possibilidade de acompanhar o movimento real das transformações na organização do trabalho e dos trabalhadores ao longo dos últimos dois séculos, propiciando elementos mais precisos para a compreensão e a crítica do suposto desfecho histórico do protagonismo da classe trabalhadora, que para muitos tem seu esgotamento histórico na configuração do processo de acumulação atual.
\end{abstract}

\section{PALAVRAS CHAVES}

Exército industrial de reserva. Trabalho. Acumulação capitalista. Habituação do trabalhador. Trabalho e Marxismo.

\begin{abstract}
This article intends to retake the Marxian definition of reserve industrial army and to follow, at least in its more general lines, the historical statements of the unfoldings of such category in the scope of the procedural dynamics of sociability. We consider that the historical investigation of the problem opens the possibility of accompanying the real movement of the transformations in the organization of work and of the workers over the last two centuries, providing more precise elements for the understanding and the critique of the supposed historical outcome of the protagonism of the working class, which for many has its historical exhaustion in the configuration of the current accumulation process.
\end{abstract}

\section{KEYWORDS}

Reserve industrial army. Job. Capitalist accumulation. Habituation of the worker. Labor and Marxism.

\footnotetext{
* Psicólogo. Doutor em Filosofia. Pós-doutorado pela UBA - Universidad de Buenos Aires/Faculdad de Filosofia y Letras sobre a ontologia no pensamento de György Lukács e Nicolai Hartmann. Em 2014 realizou pós-doutorado na Universidade Federal de Juiz de Fora, junto à Faculdade de Serviço Social. Professor Adjunto da Universidade Federal de Juiz de Fora, Faculdade de Serviço Social. Rua José Lourenço Kelmer, s/n, Campus Universitário, bairro São Pedro, Juiz de Fora (MG), CEP.: 36036-900. ORC ID: <http://orcid.org/oooo0001-9765-4913>.E-mail: <vielmi.ronaldo@ufjf.edu.br>.
}

DOI 10.22422/temporalis.2018v18n36p256-273 


\section{INTRODUÇÃO}

Decerto não é fácil sustentar a validade da determinação marxiana de exército industrial de reserva nos dias atuais, dado a vasta literatura que, a partir principalmente da década de 60 do século passado, pôs em questão a figura do trabalho e do trabalhador como protagonistas da dinâmica social. Em suas variadas vertentes que vão desde a escola de Frankfurt (nas figuras prioritárias de Jurgen Habermas e Klauss Offe), passando por André Gorz, até a leva sociológica calcada na ideia vaga e difusa da sociedade pós-industrial, hoje se assiste o entoar quase uníssono da afirmação do fim do trabalho, assim como do papel exíguo da classe trabalhadora nas tendências políticas e econômicas do mundo da economia globalizada. $O$ debate que se pretende fazer neste contexto, longe de pretender revolver o conjunto de questões complexas surgidas a partir do debate suscitado por tais ideias, pretende ao menos polemizar contra tais perspectivas, por vezes, tomadas como apodíticas. Esse artigo visa tentar demonstrar que assertivas dessa monta não são elementos passíveis de serem constatadas de maneira direta, como fatos incontestavelmente demonstrados e nem mesmo constituem afirmações evidentes por si mesmas, pois implicam a consideração de variáveis, de larga série de nuances, de mediações sociais importantes características das formações atuais, que põem em dúvida a certeza imediata de teses dessa natureza.

\section{A FORMAÇÃO DA CLASSE TRABALHADORA NO SÉCULO XIX}

Para os objetivos aqui propostos se faz necessário retomar a definição marxiana e acompanhar, pelo menos em suas linhas mais gerais, os decursos históricos dos desdobramentos de tal categoria no âmbito da dinâmica processual da sociabilidade. A consideração histórica abre a possibilidade de acompanhar o movimento real das transformações na organização do trabalho e dos trabalhadores ao longo dos últimos dois séculos, propiciando elementos mais seguros para a compreensão e a crítica do suposto desfecho histórico do protagonismo da classe trabalhadora, que culmina com a configuração atual desse processo.

Para nos limitarmos apenas às elaborações de Marx mais atinentes a nosso tema podemos remeter ao famoso capítulo 23 de sua obra maior, na qual o autor acolhe uma larga série de dados históricos no intuito de demonstrar as estratégias e mecanismos que vigoraram ao longo do século XIX no intuito de promover a criação da classe trabalhadora. Marx destaca em sua análise que a

[...] população trabalhadora excedente é um produto necessário da acumulação ou do desenvolvimento da riqueza com base capitalista, essa superpopulação se converte, em contrapartida, em alavanca da acumulação capitalista, e até mesmo numa condição de existência do modo de produção capitalista. Ela constitui um exército industrial de reserva disponível, que pertence ao capital de maneira tão absoluta como se ele o tivesse criado por sua própria conta. Ela fornece a suas necessidades variáveis de valorização o material humano sempre pronto para ser explorado, independentemente dos limites do verdadeiro aumento populacional (MARX, 2013, p. 707).

Linhas à frente o mesmo autor acrescenta: 


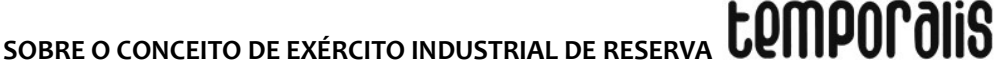

\begin{abstract}
Mas se uma população trabalhadora excedente é um produto necessário da acumulação ou do desenvolvimento da riqueza com base capitalista, essa superpopulação se converte, em contrapartida, em alavanca da acumulação capitalista, e até mesmo numa condição de existência do modo de produção capitalista. Ela constitui um exército industrial de reserva disponível, que pertence ao capital de maneira tão absoluta como se ele o tivesse criado por sua própria conta. Ela fornece a suas necessidades variáveis de valorização o material humano sempre pronto para ser explorado, independentemente dos limites do verdadeiro aumento populacional (MARX, 2013, p. 707).
\end{abstract}

Em linhas gerais, Marx aponta para o fato de o desemprego estrutural ser uma condição da sociedade capitalista. Essa superpopulação relativa é o elemento necessário capaz de fornecer aos processos de acumulação do capital não apenas a força de trabalho diretamente empregada na produção, mas igualmente uma reserva de mão-de-obra que possa vir a substituir a essa, em caso de necessidade. Trata-se da manutenção de uma superpopulação relativa apta a ser utilizada pelas indústrias tal logo seja necessário. É a garantia do próprio sistema em manter disponível esse fator imprescindível - a força de trabalho - a seu processo de reprodução, além de servir como instrumento de controle sobre os preços dos salários, pelo mecanismo da oferta e demanda do mercado de trabalho.

Merece destaque também, tal como analisa Marx no mesmo livro, a necessidade de habituar os trabalhadores às novas condições necessárias da produção capitalista. No século XIX ela implicava em seus primeiros momentos, como pressuposto para ampliação e incremento da produção, a disponibilidade de força de trabalho suficiente para ser aplicada na indústria, consentâneo à necessidade de engendrar uma nova tradição laborativa junto à classe trabalhadora. Marx refere esse processo como a criação pelo hábito e pela educação das condições sociais tidas como normais pela própria classe trabalhadora:

\footnotetext{
Não basta que as condições de trabalho apareçam num polo como capital e no outro como pessoas que não têm nada para vender, a não ser sua força de trabalho. Tampouco basta obrigá-las a se venderem voluntariamente. No evolver da produção capitalista desenvolve-se uma classe de trabalhadores que, por educação, tradição e hábito, reconhece as exigências desse modo de produção como leis naturais e evidentes por si mesmas. A organização do processo capitalista de produção desenvolvido quebra toda a resistência; a constante geração de uma superpopulação relativa mantém a lei da oferta e da demanda de trabalho, e, portanto, o salário, nos trilhos convenientes às necessidades de valorização do capital; a coerção muda exercida pelas relações econômicas sela o domínio do capitalista sobre o trabalhador. A violência extraeconômica, direta, continua, é claro, a ser empregada, mas apenas excepcionalmente (MARX, 2013, p. 808).
}

É significativo o fato de Marx destacar como elemento decisivo para o processo de acumulação capitalista a exigência de o modo de produção passar a ser assumido pelas massas, pela classe trabalhadora, como elemento naturalmente posto, algo evidente por si, na medida em que se põe como intrínseco à própria natureza da sociabilidade humana, como condição social efetiva. A habituação do trabalhador, para usar um termo posteriormente consagrado por Harry Bravermann, constitui elemento imprescindível para o estabelecimento do processo. A coerção social, por vezes desempenhada pelo Estado, não pode ser o único critério de estabilidade da forma social historicamente posta, o

Temporalis, Brasília (DF), ano 18, n. 36, p. 256-273, jul./dez. 2018. ISSN 2238-1856 
convencimento e a formação do próprio perfil das individualidades e, mais importante ainda, da própria classe trabalhadora como forma de aceitação das regras do jogo são elementos essenciais para a criação e a manutenção do status quo.

Esse aspecto pode ser observado nos primórdios da criação da grande indústria, momento em que se colocou a necessidade de reunir trabalhadores sob um mesmo teto e retirar-Ihes o planejamento e administração do próprio trabalho como forma de incrementar a produtividade. Alocar a todos debaixo do mesmo teto significava o controle sobre a atividade produtiva, além do controle do tempo trabalhado. Enquanto artesãos, os trabalhadores gestavam sua própria atividade e administravam o tempo conforme suas próprias decisões e necessidades. A esse propósito vale reproduzir as elucidativas palavras de Harry Bravermann:

O controle sem centralização do emprego era, senão impossível, certamente muito difícil, e assim o requisito para a gerência era a reunião de trabalhadores sob um único teto. O primeiro efeito de tal mudança era impor aos trabalhadores horas regulares de trabalho, em contraste com o ritmo auto-imposto que incluía muitas interrupções, meio-expedientes e feriados, e em geral impedia a extensão da jornada de trabalho para fins de produzir um excedente nas condições técnicas então existentes (BRAVERMANN, 1974, p. 66).

Acerca da mesma factualidade histórica, Norman Scott Brien Gras, em obra escrita em 1934, descreve por meio de um detalhamento minucioso as condições e situações presentes nos primórdios da instauração da indústria, momento em que ele localiza o nascimento do gerenciamento da produção.

Era simplesmente para fins de disciplina, de modo que os trabalhadores pudessem ser eficazmente controlados sob a supervisão de um capataz. Sob um teto, ou ambiente pequeno, eles podiam começar o trabalho de madrugada e continuar até o pôr do sol, fixando-se períodos para repouso e alimentação. E sob pena de perda de todo o emprego eles podiam ser mantidos por todo o ano (GRAS, 1930, p.77).

Anteriormente às alocações do trabalho nas fábricas, o comum era a produção em pequenos locais de trabalho, ou até mesmo nas próprias residências dos artesãos. Tal forma de organização do trabalho deixava praticamente todo o planejamento da atividade nas mãos dos próprios artesãos, que organizavam seu tempo em conformidade ao conjunto de outras atividades desempenhadas em seu cotidiano. Todo processo produtivo ficava, na visão do capitalista, sujeito a uma larga série de contratempos, tais como feriados, dias religiosos, atividades afins desempenhadas por esses trabalhadores artesãos, além de impedir um controle preciso do tempo gasto para a produção dos produtos encomendados. Retirar dos trabalhadores o planejamento da atividade tornou-se então imprescindível para o processo de acumulação em curso naquele momento. Para tanto tornara-se necessário o controle do tempo de trabalho. A primeira providência a causar forte impacto na transformação do trabalho desses artesãos consistiu na mudança da localização do local onde tal atividade viria a ser empreendida. Deslocar o processo produtivo das casas desses artesãos para grandes galpões, onde passou a se concentrar toda a atividade, marcou e afetou sobremaneira a vida e a prática desses trabalhadores. 
Sidney Pollard em seu livro The Genesis of Modern Management, explicitou tais processos de modo ainda mais elucidativo, já que não se restringiu à simples descrição de fatos, mas preocupou-se em destacar os aspectos mais negativos de tais decorrências históricas:

\begin{abstract}
Os trabalhadores que deixaram o ambiente de sua oficina doméstica ou sua propriedade no campo pela fábrica entraram em uma nova cultura com um novo senso de direção. Isso não foi mais do que 'a nova ordem econômica necessitava... a parte humana: sem alma, despersonalizada, desencarnada, que pôde se tornar membra, particularmente como pequenas engrenagens, de um complexo mecanismo' (POLLARD, 1968, p.190).
\end{abstract}

E mais a frente o autor acrescenta

Junto com a ligação tenaz da cultura existente e o medo do desconhecido, estava o medo do conhecido, pois foram poucas as áreas do país na qual a moderna indústria, particularmente de tecidos, se incumbiu de largos edifícios, que não estavam associados a prisões, workhouses e orfanatos. Esta conexão é usualmente negligenciada, particularmente por aqueles historiadores que assumem que os novos trabalhos recrutaram apenas trabalho livre (POLLARD, 1968, p. 192).

As observações de Pollard - que, diga-se de passagem, não é de modo algum um pilar do anticapitalismo, muito pelo contrário - são importantes de serem desdobradas. Em primeiro lugar as condições impostas eram inaceitáveis para os trabalhadores habituados à condição de planejamento de suas próprias atividades, aqueles ainda vinculados à forma artesanal da organização do trabalho. Encerrar-se em galpões fechados, sob a constante vigilância e orientação de seu trabalho por parte do supervisor, implicava não apenas o cerceamento do trabalhador, mas a perda do controle de suas atividades. Não por acaso os primeiros a se submeterem a tais condições não eram propriamente os trabalhadores livres, mas presidiários, membros das workhouses e crianças oriundas de orfanatos, cuja proveniência não lhes concedia grandes opções ou direito de escolha frente suas condições de trabalho. O trabalho em fábricas ou ateliês era compreendido como encarceramento, cerceamento, controle e desgaste evidente dos indivíduos.

Paulatinamente a nova forma da organização produtiva se impôs, em grande parte dada a sua eficácia em responder às exigências do ciclo de acumulação capitalista, tornando prática comum aos principais ramos da atividade produtiva. As gerações posteriores, vergados pela eficiência na nova forma da gestão da produção, com o tempo terminaram por tomar a nova forma da atividade laborativa como natural, algo compreendido como forma espontânea-natural da reprodução da vida.

Se retomarmos os escritos de Marx, os diversos exemplos históricos recolhidos acerca das condições do trabalho nesse período são bastantes ilustrativos desse duplo âmbito da dinâmica da acumulação capitalista do séc. XIX. O uso da maquinaria como substituição do trabalho artesanal, manufatureiro, implica tanto o aumento do numerário de trabalhadores disponíveis para o funcionamento da indústria, como aquelas atividades periféricas do próprio processo de acumulação, que sem valer-se do incremento tecnológico, aproveitou a disponibilidade crescente de mãos de obra provocada pela maquinaria nas grandes fábricas do período. $\mathrm{O}$ uso das forças subsidiárias - mulheres e

Temporalis, Brasília (DF), ano 18, n. 36, p. 256-273, jul./dez. 2018. ISSN 2238-1856 
crianças - proporcionado pelas máquinas a vapor aumenta a produtividade e, precisamente em função deste aumento, promove o incremento da disponibilidade de mão-de-obra. O excesso populacional, o crescente número de trabalhadores na condição de disponibilidade, permite o empreendimento de formas ainda manufatureiras funcionando de maneira consentânea à grande indústria. O rebaixamento acintoso dos salários compensava a baixa produtividade desses empreendimentos periféricos, com os gastos irrisórios com trabalhadores. Na revolução industrial, portanto, tem lugar a dinâmica oscilante entre o desenvolvimento da grande maquinaria na indústria, mas igualmente a exarcebação das formas mais rudimentares da produção, características da manufatura.

A competitividade levada a cabo pelos ramos mais tecnologicamente avançados, claramente acompanhada pelo aumento da produtividade e a queda dos custos de produção, é compensada pelos ramos menos desenvolvidos, pelo uso da mão-de-obra extremamente barata disponível no período em questão. Tal oferta desequilibrada de trabalhadores permite a coexistência, durante certo lapso de tempo, da produção calcada na maquinaria com as formas ainda anteriores da manufatura. Decerto, tal convívio não é algo pacífico, nem mesmo duradouro, uma vez que o curso do processo produtivo em última instância termina por se render às formas mais avançadas da produção, ou seja, à grande indústria com base na maquinofatura.

Em relação à classe trabalhadora há, portanto, dois aspectos imprescindíveis para o ciclo da acumulação capitalista: um contingente suficiente de trabalhadores empregados na atividade produtiva e outro na condição de desempregados com vista na possibilidade de substituí-los e, como segundo aspecto, com constata-se a necessidade de habituar os trabalhadores às exigências da produção, adequando-os às formas organizativas de maneira que eles passem a considerá-las como naturais, modos tradicionais e amplamente aceitos da consecução do trabalho.

\section{A TRANSIÇÃO PARA O SÉCULO XX: NOVO CICLO AMERICANO DE ACUMULAÇÃO}

A criação do exército industrial de reserva, assim como a formação da própria classe trabalhadora apareceram como elementos chaves do processo de acumulação capitalista. Tal processo não pôde, no entanto, deixar de apresentar desequilíbrios, de criar situações que implicaram de modo direto conflitos sociais agudos. Ao mesmo tempo em que criou as condições para a existência de farta mão-de-obra, as tendências postas em movimento em meio a esses processos econômicos levaram a criação de um excedente populacional, incapaz de ser absorvido pelos diversos ramos da atividade produtiva. Tal fenômeno social gerou conflitos óbvios no seio da sociedade, na medida em que uma grande massa de indivíduos não se viu inserida no mercado de trabalho, levando à formação de um contingente significativo de excluídos.

Cabe advertir, no entanto, não se trata apenas de um crescimento populacional naturalmente determinado. Outros aspectos sociais cumpriram papel de maior relevância para a formação dessa superpopulação relativa. O uso da maquinaria que propicia a absorção de forças de trabalho subsidiárias, trabalho da mulher e infantil, compõem elementos importantes da criação da disponibilidade de mão-de-obra. Mais dramático, no 


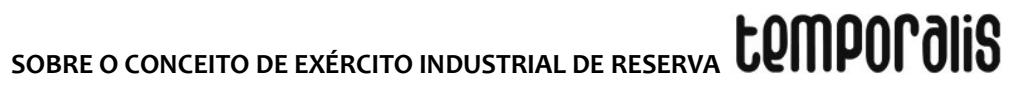

entanto, são acontecimentos históricos como é o caso da grande fome na Irlanda ou da expulsão dos camponeses de suas terras ocorridas nos estados alemães autônomos, ambos frutos das próprias tendências inerentes ao capitalismo. No primeiro caso, a grande fome irlandesa foi o resultado da divisão de terras favoráveis aos grandes latifundiários ingleses, que de uma maneira incessante e intermitente expulsavam de suas terras os camponeses. Esses tiveram que dar lugar às vastas pastagens de gado e ovelhas, à produção de cereais, cuja produção era toda ela direcionada às necessidades do mercado inglês. Ao povo irlandês restava apenas as batatas. Com a praga provocada por um fungo que se acometeu sobre o tubérculo, milhões se viram na condição de famigerados, levando à morte certa de um milhão de pessoas. No caso alemão, parte significativa dessa mão de obra excedente era constituída por camponeses espoliados de suas terras, artesãos desalojados do processo produtivo, expropriados dos seus meios de subsistência, em função do desenvolvimento da grande indústria.

Enquanto na Europa alguns países incentivavam a emigração, no outro lado do atlântico, a escassez do contingente populacional de trabalhadores constituía um problema sério para os EUA do século XIX. Ao longo de todo esse século, os EUA receberam ondas sucessivas de imigração, grande parte delas incentivadas pelo próprio governo americano. A dimensão que tal mobilidade populacional tomou ao longo do século XIX nos permite designar todo esse processo como o maior movimento de imigração da história moderna. Tal fenômeno migratório forneceu aos EUA a força de trabalho necessária para o incremento do processo de sua economia.

O processo pode ser caracterizado por duas longas ondas de migração ocorridas ao longo do século XIX destacam em linhas bem demarcadas a transferência daquela mão-de-obra excedente europeia para as terras norte-americanas. Entre as duas ondas migratórias, encontra-se a linha demarcatória decisiva identificada pela Guerra Civil dos anos 1861-5. Trata-se de acontecimento histórico de grande relevância, pois é em virtude da guerra civil que os EUA definem o perfil de seu capitalismo. Entre o sul de economia fundamentalmente agrária - calcada na exportação de commodities para a Inglaterra (fundamentalmente o algodão) - e o norte com uma base industrial já parcialmente desenvolvida, o processo histórico americano abriu as portas para a realização de sua própria revolução industrial, favorecendo um expressivo e rápido desenvolvimento de sua economia (cf. TEIXEIRA, 1999).

Para efeitos de nossa discussão não nos cabe discorrer para além dessas linhas sobre esse processo. Importa-nos destacar que em seu primeiro momento a imigração ocorrida de 1815 até a guerra civil, alimenta a economia americana fundamentalmente de mão-de-obra alocada na agricultura - plantations - além de favorecer o processo de colonização, rumo ao oeste distante - faroeste. A segunda onda de imigração permite a criação do exército industrial de reserva necessário ao processo de transformação do ciclo de acumulação americana ocorrido nos últimos anos do séc. XIX e início do séc. XX (cf. CORIAT, 1982).

Após o conturbado período da guerra civil americana, as condições para conseguir terras se mostraram praticamente impossíveis. Por diversos fatores, tais como a especulação sobre os valores da terra, assim como a colonização levada a cabo nos anos anteriores, impediram a alocação desses novos imigrantes nas atividades do campo, levando a maior 
parte a buscarem nas cidades meios para sustentar a vida. A concentração nos grandes centros criou os elementos viabilizadores para o uso desta mão-de-obra nas grandes indústrias cujo nascedouro data dos anos intermediários desses séculos.

Contudo, um problema se colocava quanto ao uso da mão-de-obra abundante. Os imigrantes que chegaram aos EUA se caracterizavam por uma total desqualificação técnica, eram trabalhadores sem preparo para a indústria. Em sua maioria, camponeses empobrecidos que nunca haviam tipo qualquer experiência nas formas da produção moderna em voga no século XIX. Nesse sentido, vale lembrar que o trabalho nessa época se dava sob o domínio preponderante dos trabalhadores de ofício, isto é, uma forma de trabalho qualificada, que pressupunha anos de aprendizagem para a sua formação. Essa mesma qualificação é responsável por outro aspecto importante: a criação dos sindicatos dos trabalhadores de ofício como elemento de resistência e obstáculo aos interesses dos capitalistas. Há dois problemas a serem resolvidos: por um lado a forte pressão e resistência da classe trabalhadora (trabalhadores de ofício) que limitava a livre ação dos capitalistas no âmbito da organização e uso da mão-de-obra, por outro, era necessário o incremento quantitativo de trabalhadores a serem usados na atividade produtiva.

A equação a ser resolvida invocava a necessidade de utilizar a grande disponibilidade de trabalhadores sem nenhuma qualificação técnica nos processos produtivos. A organização científica do trabalho cunhada por Taylor é a possiblidade de transformar uma mão de obra ociosa e sem aplicabilidade produtiva até o momento, em elemento chave para o processo de industrialização americana em curso. Em outras palavras, sua resposta é a alternativa real para as necessidades postas pelo conjunto das condições econômicas e sociais de seu tempo. Ao delegar à uma pequena elite de gerentes e engenheiros a elaboração minuciosa de toda a atividade produtiva, implicando uma gestão hiper-racionalizada do trabalho, Taylor pôs à disposição das indústrias a mão de obra não qualificada disponível, uma vez que prescinde da qualificação técnica e da capacidade de planejamento do trabalhador. 0 perfil do trabalhador é o daquele que no processo produtivo equivale ao simples dispêndio de força física, uma vez que toda sua atividade é previamente pensada e organizada por um grupo seleto de engenheiros.

Não fica de fora também desse contexto a necessidade de habituar o trabalho às novas exigência dos processos industriais. A linha de montagem proposta por Ford recebe em seus inícios uma ampla resistência por parte dos operários, que se recusam a trabalhar na nova forma organização proposta. Essa situação de resistência fica clara já nos primórdios da implementação da nova gestão do processo produtivo:

Com máquinas e chefes onipresentes supervisionando cada tarefa, pareceu não ser necessário pagamento de incentivo. Ford rapidamente descobre, entretanto, que essas condições produzem uma incrível taxa de rotatividade de trabalho. Para manter uma força média de 13 mil trabalhadores durante o tempo de prosperidade entre outubro de 1912 e outubro de 1913, Ford teve de empregar 54 mil pessoas, uma taxa de rotatividade anual de 416\% (MONTEGOMERY, 1977, p. 234).

Não será nesse caso o uso direto da violência extra econômica o elemento a ser utilizado, pelo contrário, o incentivo econômico, mais particularmente salarial, será o responsável por vergar a classe trabalhadora às novas exigências. O famoso caso da oferta salarial de 
D\$ 5,00 por dia oferecidos por Henri Ford para um conjunto bem seleto de trabalhadores que cumpriam as exigências de seus gerentes, a redução da jornada de trabalho de 9 para 8 horas, trouxe às dependências de sua indústria a força de trabalho necessária a seus empreendimentos e fez com que, apesar de desgastantes e inóspitas, as novas condições de trabalho fossem aceitas por todos.

Vale lembrar que esses elementos motivadores não eram aplicados de maneira indiscriminada a todo trabalhador. As condições exigidas dirigiam-se aos trabalhadores que demonstravam clara adesão às novas prerrogativas da empresa e visavam diretamente a formação do perfil necessário dos trabalhadores aptos a aceitar e desempenhar as novas funções projetadas.

[...] em janeiro de 1914, Ford proclama as 8 horas diárias e o novo plano de 'participação nos lucros' para todos os empregados. Qualquer homem ou mulher acima de vinte e dois anos que contribuísse apoiando aos outros, trabalhasse na companhia seis meses ou mais, e fosse considerado como 'aceitável' pelo Departamento Sociológico da companhia era elegível para o 'share profit', recebendo o salário de cinco dólares por dia. O staff de mil 'sociólogos' investigava os hábitos, a vida no lar e as atitudes dos trabalhadores para descobrir quem era aceitável e no final de março de 1914 foram aprovados 57\% desses para receber os mágicos cinco dólares (MONTEGOMERY, 1977, p. 235).

Nesse caso também há a necessidade da formação do exército industrial de reserva e da habituação do trabalhador como critérios imprescindíveis do ciclo de acumulação capitalista. A resistência das primeiras gerações é quebrada, para na sequência se tomar como normal o modus operandi das novas relações e organização do trabalho. Quer pela coerção, pela motivação ou pela cooptação, os mecanismos da habituação do trabalhador dão provas históricas de sua eficácia.

Outro caso clássico da ofensiva e a adestração promovida contra a classe trabalhadora teve curso duas décadas antes no Japão. Trata-se no nascimento do toyotismo que implicou não apenas mudanças expressivas na gestão do trabalho, na organização das empresas, mas igualmente o ataque frontal às formas da organização sindical dos trabalhadores, como pressuposto viabilizador das mudanças necessárias de serem perpetradas. Pouco se comenta sobre o desmantelamento dos sindicatos de trabalhadores ocorrida nos idos de 1950 e 1953. Por meio de uma clara aliança entre o setor industrial e o setor financeiro japonês foi possível, por exemplo, à empresa Nissan - apoiada em suas estratégias pelo banco Fuji Bank, pertencente à mesma companhia - sustentar-se por quase um ano de greve, quebrando de maneira definitiva toda a resistência da classe trabalhadora no período. Com prisões das lideranças e o desmantelado consumado dos sindicatos se tornou possível o implemento das novas condições de trabalho, forçando deliberadamente os trabalhadores a adesão incondicional aos interesses das empresas (cf. GOUNET, 2002, p.30-31).

Após as medidas coercitivas, incentivos são aplicados para forjar o novo modelo de trabalhador adequado às novas exigências gerenciais. $O$ mais famoso deles é o emprego vitalício para os trabalhadores permanentes das grandes companhias. No entanto, é preciso advertir os limites e as verdadeiras intenções por trás de tais benefícios concedidos: 
[...] o emprego vitalício é apanágio dos trabalhadores fixos da empresa-mãe. Só podem contar com ele os empregados com contrato por tempo indeterminado e que trabalham nas montadoras automobilísticas. Os que se encontram em regime de subcontratação, particularmente os das pequenas e médias empresas, não possuem o mesmo direito. Ora os operários das grandes empresas não representam mais que um terço da mão-de-obra assalariada. Isso significa que dois trabalhadores em cada três não tem estabilidade no emprego. Além disso, a própria Toyota a partir de 1956 começou a contratar temporários. Em 1961, menos da metade dos operários que trabalhavam nas fábricas da empresa eram estáveis (GOUNET, 2002, p. 100-101).

O toyotismo não significa apenas a gestão da força produtiva, mas de maneira consentânea mudanças decisivas na organização da empresa. O modelo das terceirizações, as subcontrações, é um elemento decisivo da nova forma da gestão empresarial. Claramente a terceirização fragiliza a organização da classe trabalhadora na medida em que a fragmenta em uma diversidade de empresas o próprio processo produtivo. Tal fragilização e controle da mão-de-obra fomenta a produtividade e ao mesmo tempo reduz custos relativos ao pagamento de salários. Esses são elementos chaves no recrudescimento da competitividade japonesa no comércio internacional, particularmente a partir da década de 1960.

A situação se mantém em uma linha de continuidade até à nova grande crise do capital ocorrida ao final da década de 60 e início da década de 70 no século XX. Ao longo dessa grande crise, assistiu-se novamente medidas bem semelhantes à que descrevemos nesses outros momentos. Uma nova ofensiva contra a classe trabalhadora teve curso, além de claramente a necessidade de criar uma nova forma da organização do trabalho e de encontrar condições satisfatórias em relação à disponibilidade de mão-de-obra a ser alocada no processo de produção.

\section{A CRISE MUNDIAL E AS MUDANÇAS NA GESTÃO DO TRABALHO}

A vigência atual e o sucesso do toyotismo não devem ser vistos como simples elementos oriundos da eficiência técnica dessa forma de gestão. Vale lembrar que seus primórdios estão postos na década de 1950, mas sua eficácia e projeção internacional inicia-se de maneira mais precisa na década de 1970. O que explica sua projeção hegemônica, principalmente na indústria automotiva, são os novos componentes históricos do ciclo de acumulação capitalista do período.

Em termos gerais podemos dizer, as transformações no mundo do trabalho são consequências do movimento próprio aos ciclos de acumulação capitalista. A esse propósito são necessárias algumas ponderações, ainda que rápidas e circunscritas ao nosso tema, no intuito de entender a correlação entre as metamorfoses do trabalho e as determinantes econômicas próprias do período.

Quem nos ajuda a compreender essa dinâmica é o historiador marxista Robert Brenner. Para o autor,

A partir de meados da década de 1960, os fabricantes localizados nos blocos econômicos de desenvolvimento mais tardio - mais notadamente no Japão, mas também na Alemanha e em outras partes da Europa ocidental - foram, portanto, 
capazes de combinar técnicas relativamente avançadas com salários relativamente baixos para reduzir de forma drásticas os custos relativos de suas produções em comparação àqueles necessários para produzir os mesmos bens na economia americana, de desenvolvimento anterior. Desse modo, eles não só conseguiram impor seus preços relativamente baixos no mercado mundial e inchar de modo dramático as suas cotas desse mercado, como foram também capazes, precisamente em virtude de seus custos relativamente reduzidos, de ao mesmo tempo manter suas antigas taxas de lucro. Os produtores americanos, portanto, se viram confrontados com preços para os seus produtos que apresentavam um crescimento mais lento, mas se encontravam amarrados a custos inflexíveis por se acharam atravancados por instalações e equipamentos (capital fixo) que incorporavam métodos de produção que se tornaram subitamente muito caros, bem como por níveis salariais relativamente altos, que não podiam ser empurrados para baixo de forma rápida (BRENNER, 2001, p. 56).

Em termos sintéticos, para o autor, esse período é caracterizado pela crise de superprodução, ou em outros termos, a crise provocada pelo excesso de capacidade instalada. O agravamento da situação incidiu não muito tempo depois sobre as próprias economias do Japão e da Alemanha, generalizando-se para todos as economias do mundo. Brenner, insiste em demonstrar que os elementos mais decisivos dessa crise não foi sequer superado nos dias atuais, caracterizando aquilo que ele designa como estagnação persistente.

Não é o lugar aqui para desenvolver de maneira minuciosas tais questões, para nós importa as consequências diretas que toda esta situação acarreta na dinâmica capitalista de acumulação, e minimamente relacioná-la com o problema da necessidade da reorganização do fator econômico força de trabalho, como mote para minimamente equacionar aspectos da crise de fim de ciclo de acumulação capitalista.

Que nos seja permitido retornar mais uma vez a Marx, já que é em tal pensador que a categoria em tela nesse artigo tem sua origem. Marx, no livro III, capítulo 14, de O capital apresenta seis contratendências que atuam como forças contrárias à queda tendência da taxa de lucro, são elas: I- aumento do grau de exploração do trabalho; Il- compressão do salário abaixo de seu valor; III- barateamento dos elementos do capital constante; IV- a superpopulação relativa; V-comércio exterior e VI- aumento do capital acionário (Marx, 2017). Dentre os seis relevantes pontos das tendências contra arrestantes, ao menos três se relacionam de maneira mais direta com os propósitos de nossa discussão. Em relação ao primeiro ponto, cabe destacar o papel do desenvolvimento científico e tecnológico no aumento da produtividade da força de trabalho. Esse sem dúvida, ao lado da ofensiva contra o trabalho, é um dos fatores decisivos do processo de acumulação hoje em curso. Aqui cabe apenas mencioná-lo, pois a complexidade da questão impõe o tratamento em separado de tal temática. O segundo ponto, é evidente por si mesmo, a compressão dos salários implica menos gastos e o aumento da taxa de retorno ao capitalista. O terceiro ponto, quarta tendência relacionada por Marx, está diretamente relacionado com a nossa questão, permite minorar os efeitos da queda tendencial por meio da utilização da mão de obra excedente. Essa pode tanto contribuir criando um excesso de competitividade entre os trabalhadores, como pode também permitir o uso da mão-de-obra disponível na criação de novos ramos de produção, onde a composição orgânica de capital pode vir a se caracterizar pelo grau mais elevado de uso de trabalho vivo. Nesses ramos, a vantagem consistiria na presença massiva do capital variável associado aos baixos rendimentos dos

Temporalis, Brasília (DF), ano 18, n. 36, p. 256-273, jul./dez. 2018. ISSN 2238-1856 
trabalhadores provocados particularmente pela concorrência entre trabalhadores. Retomaremos esse ponto logo à frente.

Ao voltarmos nossa atenção aos acontecimentos nos EUA, podemos vislumbrar a presença histórica de algumas dessas tendências. A crise da economia mundial gerou o aumento do desemprego, que conjuntamente a outros fatores favoreceram a forte ofensiva contra a organização da classe trabalhadora. Dados estatísticos demonstram que entre o período de 1973 e 1979, os fabricantes americanos conseguiram a "[...] reduzir a média anual de crescimento dos salários reais por hora de trabalho para 1\% comparada aos $2 \%$ entre 1970 e 1973. De 1979 a 1995, essa média anual despencou para 0,65\%” (BRENNER, 2003, p.99).

As perdas dos trabalhadores do setor automotivo americano ilustram bem essa tendência do período. Mecanismos conquistados ao longo de anos que permitiam aos trabalhadores americanos ganhos reais em seus salários, como por exemplo o AIF e o COLA 1 , a partir de 1979, declinam frente as condições catastróficas impostas pelas indústrias automotivas americanas. Do mesmo modo, a flexibilidade permitida pelo modelo toyotista na exploração dos trabalhadores, leva a termo acordos como o Job Control System ${ }^{2}$, impondo às empresas americanas o novo modelo produtivo advindo do Japão. Thomas Gounet demarca as vantagens que o toyotismo obtinha sobre a velha forma da gestão fordista da produção:

\begin{abstract}
A flexibilidade do aparato produtivo e sua adaptação às flutuações da produção acarretam a flexibilização da organização do trabalho. O parcelamento das tarefas do fordismo já não é suficiente. As operações essenciais do operário passam a ser, por um alado, deixar as máquinas funcionarem e, por outro, preparar os elementos necessários a esse funcionamento de maneira a reduzir $o$ máximo o tempo de não-produção. Assim, rompe-se a relação um homem/uma máquina. Na Toyota, desde 1955 um trabalho opera em medida cinco máquinas (GOUNET, 2002, p. 27).
\end{abstract}

Foi necessário quebrar toda a resistência proveniente da classe trabalhadora para modificar a organização produtiva americana e para isso várias estratégias foram utilizadas, porém a de maior efeito foi sem dúvida a ameaça da possibilidade de, na crise, as empresas optarem pela demissão de trabalhadores.

É ilustrativo dessas ofensivas contra a classe trabalhadora um dos primeiros atos da presidência de Ronald Reagan. Conforme lembra o economista americano Robert Brenner,

[...] a administração Reagan desferiu o coup de grâce no movimento trabalhista americano ao demitir os membros em greve do sindicato dos profissionais

\footnotetext{
1 “AIF (Annuel Improvement Factor) era um dispositivo que previa um aumento automático e sistemático do salário horário nominal em torno de $3 \%$ ao ano. O COLA (Cost of Living Adjustement) garantia uma indexação automática e quase completa dos salários sobre a inflação (índice de preços)" (CORIAT, 1990, p. 235).

2 "É uma das particularidades do sindicalismo americano que a tradição do sindicalismo de ofício impõe sempre fortemente. Praticamente, são definidos por tipo de ofício regras de trabalho (Work rules) bastante rígidas: tipos de tarefas que cada categoria de trabalhadores deve executar (as tarefas que não figuram na lista não podem ser impostas ao operador concernente), número de peças por hora, etc. É portanto uma forte rigidez que pesa sobre o sistema americano em relação a outros sistemas (francês ou italiano por exemplo)" (CORIAT, 1990, p. 235).
} 


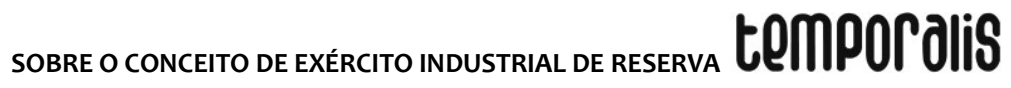

controladores de tráfego aéreo (o PACTO). Desde então as campanhas sindicais definham ao ponto da insignificância, pupularam práticas trabalhistas injustas cometidas pelas gerências durante campanhas de organização sindical e a densidade sindical desmoronou (BRENNER, 2003, p.98-99).

Além desse confronto direto dirigido aos direitos trabalhistas, na mesma administração de Reagan tem início a redução dos investimentos do Estado nos benefícios e políticas sociais. Assomados ao discurso liberal, a redução dos gastos públicos - que incidiu prioritariamente sobre os chamados custos sociais, com medidas que afetaram diretamente a saúde, a cobrança de mensalidades nas universidades, etc. - permitiu a redução dos impostos, beneficiando as empresas americanas e conferindo a elas novo fôlego na medida que tais medidas favoreciam o aumento - ainda que provisório - de sua taxa de lucro. Em suma, o entoar neoliberal adverte para a necessidade da redução dos gastos públicos no intuito de reduzir impostos como forma de aliviar também a pressão da carga tributária sobre os lucros. As medidas adotadas por Reagan durante seu governo, promoveram uma série de reduções na arrecadação, associado ao crescente déficit público do governo americano, viabilizou a redução dos impostos no setor manufatureiro da taxa média de $46 \%$, no período de 1965 a 1981, para 28\% entre 1981 e 1990 (Cf. BRENNER: 2003, p. 99).

Devemos, entretanto, retornar ao problema central de nossa discussão, qual seja, o papel do exército industrial de reserva no ciclo de acumulação capitalista de nossos dias.

\section{DESLOCALIZAÇÃO DA PRODUÇÃO E OFERTA INTERNACIONAL DE TRABALHO}

Passados quase cinquenta anos, em meio a crescimento e abalos econômicos a situação muda em suas linhas de adoção de medidas mais gerais, porém mantém, guardadas as devidas diferenças e especificidades, os fundamentos anteriormente postos em destaque. Ainda é necessária a articulação entre a disponibilidade de mão-de-obra e a formação dessa em conformidade às novas condições de trabalho.

A esse propósito vale acrescentar que com o esquema geral da organização produtiva advinda de maneira mais contundente com o toyotismo foram lançadas as bases da forte onda de terceirização das empresas e da tendência cada vez mais forte ao uso da deslocalização do processo produtivo, elementos que se tornaram preponderantes como alternativas diante da crise da década de 70. Não queremos com isso afirmar, como vemos de costume, o toyotismo como a forma hegemônica do novo ciclo de acumulação, porém merece destaque o fato de elementos específicos provenientes dessa forma de organização do trabalho responderem de maneira adequada às novas exigências postas pela dinâmica da economia próprias dos novos tempos. Em particular os elementos da terceirização e da deslocalização da produção têm constituído uma das mais fortes tendências dos últimos tempos. A deslocalização, talvez o aspecto mais relevante para a discussão aqui em curso, consiste na tendência de conduzir o processo produtivo para fora do próprio país de origem, de forma que a busca pela disponibilidade de mão-de-obra e pelas vantagens oferecidas pela precária regulamentação das leis trabalhistas em certas regiões do mundo, passa a não mais se limitar às fronteiras do próprio país, estendendo-se para outras regiões do globo que oferecem condições mais favoráveis às empresas. Países como México, Indonésia, China, Taiwan, dentre outros, aparecem como alternativas viáveis para o uso de um exército industrial de reserva posto agora em um plano internacional. 
Nos dias atuais, há de se destacar o papel da China na divisão internacional do trabalho, como componente que ilustra de maneira evidente as novas tendências implementadas. Esse aspecto não pode ser negligenciado uma vez que a partir da década de 1990 torna-se expressivo o número de corporações internacionais a produzir nesse país, chegando por vezes, a abandonar definitivamente o próprio território de origem.

Do ponto de vista da formação do exército industrial de reserva alguns dados sobre a China, quando comparados a outras regiões do mundo, demarcam ainda a validade desse fator enquanto elemento decisivo dos processos de acumulação do capital.

\begin{abstract}
A população ativa empregada na indústria e na construção contava com mais de 160 milhões em 2001, dentre os quais 65-70 milhões nas cidades (compreendido aí os desempregados) e 90 milhões nas zonas rurais (compreendido aqueles que tem um emprego temporário nas vilas). O número de trabalhadores na indústria na China ultrapassa a soma de todos os países da OCDE (131 milhões). No setor industrial urbano, ele ultrapassa o da União Europeia e dos EUA tomados conjuntamente (64 milhões). Ele eclipsa também os recursos de mão-de-obra mobilizados na indústria de outros grandes países em desenvolvimento: 9 milhões no Brasil, 13 milhões na Indonésia, 25 milhões na Índia (LEMOINE, 2013, p. 50).
\end{abstract}

Que se ressalte aqui novamente, esses números se reportam tão somente à alocação de mão-de-obra no setor industrial, no caso chinês em outros ramos da economia esse quantitativo cresce a patamares exorbitantes. Não por acaso, no decorrer de todo esse período a China assumiu os ares de uma nação que estava por se constituir como a fábrica do mundo.

No entanto, as vantagens da situação do trabalho chinês para os empreendimentos das grandes corporações não consistem apenas no enorme contingente de mão de obra disponível cuja jornada de trabalho é de 12 horas diárias, nem com a reduzida condição regulatória própria do início do século, e nem ainda, com o baixo preço da força de trabalho. Outro fator aparece igualmente como decisivo: a flexibilidade do trabalho.

Quem nos mostra outro aspecto são os dirigentes da gigante Apple, ao descrever de maneira aberta e franca o critério decisivo que os levaram a adotar a deslocalização da produção. Eles lembram que não foi difícil para Apple organizar sua produção na China, haja vista que na montagem e preparação para a produção do iPhone a empresa, por meio da Foxconn (corporação de Taiwan), foi capaz de recrutar certa de 8.700 engenheiros industriais e mais de 200 mil trabalhadores em apenas 15 dias; enquanto, por estimativa, essa mesma proporção de mobilização de mão-de-obra em um país como os EUA levaria pelo menos 9 meses para se efetivar. Outra vantagem, segundo um ex-executivo da firma de Cupertino, consiste no fato de toda a cadeia de suprimentos necessários se localizar no interior da própria China: "Você precisa de mil juntas de borracha? Basta bater na fábrica ao lado. Precisa de um milhão de parafusos? A fábrica para isso está a um quarteirão de distância. Quer que o parafuso seja um pouco diferente? Isso leva apenas três horas para ser feito." 
Caso exemplar, bastante ilustrativo dessas vantagens, ocorreu nos idos de 2007 por ocasião do lançamento do iPhone. Há um mês do lançamento do iPhone, Steve Jobs chamou uma reunião com seus principais diretores e mostrou a tela de seu aparelho arranhada para os presentes. Conta-se que ele dirigiu a todos com as seguintes palavras: "As pessoas vão carregar esse telefone em seus bolsos. Elas também carregam suas chaves no bolso. Eu não vou vender um produto que fica arranhado. Eu quero uma tela de vidro, e eu o quero perfeito em seis semanas" (DUHIGG; BRAKSHER, 2012).

Após a reunião, imediatamente, foram tomadas providências para sanar o problema:

\begin{abstract}
Em meados de 2007, após um mês de experimentos, engenheiros da Apple finalmente aperfeiçoaram o método para reduzir arranhões no vidro, então ele pode ser usado na tela do iPhone. A primeira carga de telas chegou à cidade da Foxconn no silêncio da noite, de acordo com um antigo executivo da Apple. Foi quando o gerente acordou milhares de trabalhadores, que vestiram seus uniformes - branco e preto para homens, vermelhos para mulheres - e rapidamente se alinharam para montar, com as mãos, os telefones. Em três meses, Apple vendeu um milhão de iPhones. Após isso, Foxconn montou aproximadamente mais 200 milhões (DUHIGG; BRAKSHER, 2012).
\end{abstract}

Em comparação aos trabalhadores americanos, os chineses apresentam a flexibilidade necessária capaz suprir as exigências da empresa. De maneira direta Jennifer Rigoni, exgerente de suprimentos da Apple na China, declara a esse respeito: "em que fábrica nos EUA pode encontrar 3.000 pessoas durante a noite e convencê-los a viver em dormitórios? Há uma ampla flexibilidade do trabalho na China que a coloca como mais vantajoso para produzir do que em países excessivamente regulamentados e com uma classe trabalhadora organizada, como é o caso dos EUA.

Não por acaso, o famoso jantar oferecido por Barak Obama ao CEO da Apple, Steve Jobs (cf. DUHIGG; BRAKSHER: 2012), no qual o presidente americano o interpela sobre a possibilidade de retornar postos de trabalho para a nação americana, recebeu um taxativo não como resposta. Hoje, a insistência do atual presidente americano, Donald Trump sob a bandeira do make America great again, impõe fortes pressões para forçar a empresa a retornar sua produção nos EUA, algo somente possível mediante absurdas concessões do governo americano às exigências cada vez mais vorazes da corporação em questão (redução de impostos para repatriação de capital, privilégios para a instalação da Foxconn em Wisconsin etc.).

A permissibilidade da deslocalização do trabalho também viabiliza às grandes corporações escapar da pressão da organização dos trabalhadores em seu próprio país e aproveitar condições mais vantajosas oferecidas por outras nações; ao mesmo tempo se valem da enorme disponibilidade de mão-de-obra presente em um país, por exemplo, como a China. Nesse caso, a alocação de trabalhadores em seu processo produtivo, assim como o exército industrial de reserva já não se encontra mais dentro dos limites das fronteiras de seu próprio país. A diminuição de empregos nos EUA encontra-se diretamente associada a essas novas tendências, e porque não ver nessa mesma dinâmica de deslocalização um mecanismo de controle capaz de promover a redução do preço da força de trabalho nos EUA. 
Seja pela redução dos custos salariais, seja pela desregulamentação das leis trabalhistas, seja pela flexibilização do trabalho, ou ainda, pela oportunidade de escapar das pressões das leis trabalhistas e das organizações dos trabalhadores de seu próprio país, a opção de grandes corporações ainda se pauta em dois critérios decisivos: a necessidade da superpopulação relativa e a ofensiva contra a organização da classe trabalhadora.

Em relação a esse último critério vale lembrar o impacto internacional provocado por essa grande oferta de mão-de-obra proporcionada por países periféricos. Em grande medida redundou na desregulamentação das leis trabalhistas em diversos países centrais. Apenas para citar en passant um caso dentre os mais importantes: na Alemanha em 2003, a designada Agenda 2010, levou ao congelamento de salários e deu origem a um amplo setor de trabalhadores de baixa remuneração (400 euros). Além disso, para citar apenas as medidas mais centrais de tal plano: 1) promoveu um modelo de terceirização baseado em trabalho temporário ou de subcontratação; 2) permitiu a redução da aposentadoria para o patamar de $60 \%$ do último salário recebido na ativa, e, consentaneamente, 3 ) implicou o aumento da idade mínima necessária para a aposentadoria, que passou de 65 para 67 anos; 4) permitiu a redução nos custos empresariais na demissão de trabalhadores (Cf. RIGOLLETO; PÁEZ, 2018).

O efeito de tais medidas se alastrou para a Espanha, cuja reforma trabalhista se deu em moldes muito próximos aos alemães no ano de 2012, e para Itália, com o Act Jobs, em vigor desde 2015. As mesmas tentativas de mudanças nas leis trabalhistas geraram na França forte onda de protestos que, mesmo com grandes resistências de trabalhadores e estudantes, não conseguiu conter a onda reformista que acometeu o velho continente. Essa tendência reformista foi a resposta orquestrada para conter ou amenizar a crise que assola a economia mundial desde 2008 e já se fizera presente em $2001^{3}$.

Em linhas gerais as reformas significam a redução da pressão dos salários sobre os lucros, fomentado tanto pelo retorno às formas do século XIX de exploração do trabalho por meio da mais valia absoluta - ou seja, aumento da jornada de trabalho -, como por mecanismos de redução dos salários. A produção em países cujo preço dos salários é mais baixa, associado à flexibilidade da regulamentação e da mão-de-obra se tornou um mecanismo eficaz para conduzir os gastos salariais a patamares mais baixos. Junto a isso, medidas tributárias tendem a reduzir os custos dos gastos sociais. $O$ ensejo é retornar às realizações próximas àquelas realizadas por Reagan que durante seu governo. Em síntese, tais medidas têm como primazia conter a crise da queda tendencial da taxa de lucro, fenômeno que tem se intensificado de maneira flagrante a economia mundial nas últimas duas décadas.

O Brasil tardiamente assume seu lugar na fila das reformas. Obviamente a natureza de nossas reformas são mais perversas diante da particularidade tacanha da economia e da sociedade brasileira. A reforma trabalhista brasileira segue a linhas das tendências internacionais, consistindo em um modo desesperado de a classe capitalista brasileira fazer frente às condições cada vez mais rígidas de exploração do trabalho hoje em curso no mundo. De igual maneira prepara as bases para a redução dos custos sociais de nossa

\footnotetext{
3 Não é simples coincidência o fato da reforma trabalhista alemã ter ocorrido 2 anos após a grande crise na economia mundial ocorrida em 2001.
}

Temporalis, Brasília (DF), ano 18, n. 36, p. 256-273, jul./dez. 2018. ISSN 2238-1856 
sociedade, como forma de aliviar também a pressão tributária sobre o lucro das empresas. A reforma da previdência atende a essa segunda alternativa à crise.

Tudo o que dissermos nos permite ponderar: se ainda é possível insistir na validade da definição marxiana podemos então dizer que o exército industrial de reserva não se limita mais às fronteiras de um país, mas tem a dimensão da oferta mundial de mão-de-obra. Além disso, é possível mediante tais considerações problematizar a concepção fácil e não devidamente argumentada acerca da pouca relevância do trabalho e da figura do trabalhador nas novas condições da sociabilidade de nossos dias. O que de fato assistimos na atualidade é a complexificação das formas de exploração do trabalho, associadas a uma grande ofensiva contra a classe trabalhadora, capaz de atenuar sua organização e resistência diante dos ataques aos direitos conquistados por anos de intensa luta. Podemos dizer que as questões relativas ao trabalho já não dizem respeito apenas às circunstâncias nacionais, às particularidades de cada país, mas o que ocorre em uma nação resvala suas consequências diretamente em outras nações. Nesse sentido, mais do que antes, a alternativa para a classe trabalhadora nos conduz novamente à famosa frase que encerra o Manisfesto do Partido comunista de Marx e Engels:

Trabalhadores de todo o mundo uní-vos!

\section{Referências}

BRAVERMANN, Harry. Trabalho e capital monopolista: a degradação do trabalho no século XX. Rio de Janeiro: Guanabara, 1974.

BRENNER, Robert. O boom e a bolha: os Estados Unidos na economia mundial. Rio de Janeiro: Record, 2003.

BRENNER, Robert. The Economics of Global Turbulenc. London-New York: Verso, 2006.

CORIAT, Benjamin. El taller y el cronometro. México: Siglo XXI, 1982.

CORIAT, Benjamin. L'atelier et le robot. Paris: Chistian Bourgois, 1990.

DOBB, Maurice. A evolução do capitalismo. Rio de Janeiro: Zahar, 1977.

DUHIGG, Charles; BRAKSHER, Keith. How the U.S. lost out on iPhone work. The New York Times, n. 21, jan.2012.

GOUNET, Thomas. Fordismo e Toyotismo na civilização do automóvel. São Paulo: Boitempo, 2002.

GRAS, Norman S. B. Industrial evolution. Cambridge/Massachusetts: Harvard University Press, 1930.

LEMOINE, Françoise. L'économie chinoise. Paris: Éditions La Découverte, 2003. 


\section{tempordils}

FORTES, RONALDO VIELMI

MARX, Karl. O capital: crítica da economia política, livro 1: o processo de produção do capital. São Paulo: Boitempo, 2012.

MARX, Karl. O capital: crítica da economia política, livro 3: o processo global de produção capitalista; São Paulo: Boitempo, 2017.

MONTEGOMERY, David. The fall of the house of labor. Cambridge: Cambrige University Press, 1977.

POLLARD, Sidney. The genesis of modern Management. Harmondsworth: Penguin, 1968.

RIGOLETTO, Tomás; PÁEZ, Carlos Salas; As experiências internacionais de flexibilização das leis trabalhistas. In: KREIN; GIMENEZ; SANTOS (Orgs.). Dimensões críticas da reforma trabalhista no Brasil. Campinas: Curt Nimuendaujú, 2018.

TEIXEIRA, Aloísio. Estados Unidos: a curta marcha para a hegemonia. In: FIORI, José Luiz (Org.). Estados e moedas no desenvolvimento das Nações. Petrópolis: Vozes, 1999. 